\title{
Climate downscaling: techniques and application
}

\author{
B. C. Hewitson ${ }^{1, *}$, R. G. Crane ${ }^{2}$ \\ 'Department of Environmental and Geographical Sciences, University of Cape Town, Private Bag, \\ Rondebosch 7700, South Africa \\ ${ }^{2} 104$ Deike Building, The Pennsylvania State University, University Park, Pennsylvania 16802, USA
}

\begin{abstract}
Downscaling, or translation across scales, is a term adopted in recent years to describe a set of techniques that relate local-and regional-scale climate variables to the larger scale atmospheric forcing. Conceptually, this is a direct evolution of more traditional techniques in synoptic climatology; however, the downscaling approach was developed specifically to address present needs in global environmental change research, and the need for more detailed temporal and spatial information from Global Climate Models (GCMs). Two general categories exist for downscaling techniques: process based techniques focused on nested models, and empirical techniques using one form or another of transfer function between scales. While in the long term nested models hold the greatest promise for regional-scale analysis, this approach is still in development, requires detailed surface climate data, and is dependent on high end computer availability. Conversely, empirical relationships offer a more immediate solution and significantly lower computing requirements, consequently offering an approach that can be rapidly adopted by a wider community of scientists. In this paper, an application of empirical downscaling of regional precipitation is implemented to demonstrate its effectiveness for evaluating GCM simulations and developing regional climate change scenarios. Gridded analyses of synoptic-scale circulation fields are related to regional precipitation using neural nets. Comparable GCM circulation fields are then used with the derived relationships to investigate control simulation and doubled atmospheric $\mathrm{CO}_{2}$ simulation synoptic-scale forcing on regional climates.
\end{abstract}

KEY WORDS: Downscaling · Artificial Neural Nets $\cdot$ Climate change

\section{INTRODUCTION}

A primary objective of climatology and the analysis of atmospheric dynamics is the application of climate data and atmospheric analysis to issues related to society and those aspects of the physical environment that impact on the human system. For example, the motivation behind research ranging from daily forecasting through to drought and extreme event analysis is invariably based on society's need to accommodate and adapt to the impacts of the climate system. This is very evident in the societal need to respond to global environmental change, along with the need to anticipate probable future changes in the climate system. While for some regions of the globe this is of more critical concern than for others (for example, poorer

\footnotetext{
•E-mail: hewitson@hickory.egs.uct.ac.za
}

nations with more fragile economies and agricultural infrastructures), there is nonetheless a global need for understanding the possible impacts of climate change and variability.

In contrast to the global nature of the atmospheric forcing, the focus, when considering the societal response, is on regional impacts and the local consequences of large-scale change. It is in this area, however, that analysis techniques are weakest. Although Global Climate Models (GCMs), the primary tools for investigating global change, provide reasonable simulation accuracy of present climate when viewed from global, hemispheric, and continental scales, data at the models' finest scale of representation (typically 2 to 4 degrees of latitude or longitude) are often found to be highly erroneous, especially in the important area of hydrology. The skill level of the model (von Storch et al. 1993) is substantially different from the actual model resolution, with the skill level for many parame- 
ters increasing as they are averaged over a larger and larger grid (Grotch \& MacCracken, 1991). In contrast, the primary needs of a society attempting to plan for or respond to climate change lie at far finer spatial resolutions (e.g. catchments). For example, while GCM accuracy decreases as spatial scales become finer, in hydrological, as in most other applications, one usually needs increasing detail as spatial scales decrease (e.g information on individual rainfall events in a catchment basin to determine runoff and storage); consequently, the scales of accuracy of GCMs are in direct opposition to that of societal need. Thus while GCMs provide skill levels in terms of many degrees of latitude and longitude, and are best at temporal scales of monthly means and longer, the needs for impacts research are at spatial scales of the order of $100 \mathrm{~km}$ or better and temporal scales which capture the episodic nature of the climate behavior.

A number of approaches can be adopted to meet such needs. At present, these fit into 2 categories: process based techniques, involving the explicit solving of the physical dynamics of the system; and empirical techniques that use identified relationships derived from observational data. Either approach may be adopted for developing regional climate change scenarios, and both have advantages and shortcomings.

Table 1 identifies some of the range of options available for regional scenario development in each of the 2 categories. For example, with process based techniques, it is possible to use simplified 1-dimensional or 2-dimensional models which may be run for a specific location, or perhaps more complex 3-dimensional models. However, for the more sophisticated models this is a computationally expensive choice, and requires significant development time. Alternatively, an example of an empirical technique is to develop analogues using existing or paleo situations as surrogates for possible future climates. This, however, involves some serious assumptions, such as that the processes giving rise to the analogues will be the same under future climates forced by a rapid doubling of atmospheric $\mathrm{CO}_{2}$. Highlighted in the table within each category is the downscaling approach based on atmospheric circulation. This specific option concerns the derivation of local-scale information from the larger scale circulation dynamics and forms the focus of the rest of this paper.

\section{DOWNSCALING AND SYNOPTIC CLIMATOLOGY}

The explicit use of the term 'downscaling' in climatological applications has only recently become widespread. Nonetheless, conceptually the application of downscaling has been with us for many years in the form of techniques that translate across spatial scales, such as from the synoptic to the regional and local scales. In this context, many examples of downscaling may be found in the literature from the early 1960 s onward. During this period a number of techniques were developed to categorize the atmospheric circulation and relatc these generalized groupings lo local climate or environmental conditions. The term synoptic climatology was first used in the early 1940s, but its roots can be traced to much earlier work in England during the late nineteenth century and in Germany during the 1930s. This earlier work is summarized by Barry \& Perry (1.973) who state that 'the field of synoptic climatology is concerned with obtaining insight into local or regional climates by examining the relationship of weather elements, individually or collectively, to atmospheric circulation processes.' This definition of synoptic climatology effectively encompasses the objectives of downscaling, and in this respect downscaling may be seen as a logical extension, or even evolution, of synoptic climatology. Nonetheless, an important distinction between this definition and downscaling (as described here) lies in synoptic climatology's use of discrete types, or classes, of weather systems. In doing so the circulation data are effectively categorized with consequent loss of information about the continuous nature of the system.

The approaches used in synoptic climatology to class or type circulation systems are diverse, although to some degree there has been an emergence of 'standard' procedures in the literature (see for example Yarnal 1993) and their application has been widespread. However, while such empirical techniques

Table 1. Some of the options available for regional climate scenario development. The technıques in bold type represent the downscaling option for process and empirically based techniques

Process based techniques

GCMs/multiple GCMs

Simplified $1 D$ and $2 D$ models

Mesoscale and high resolution 3D models

Nested model downscaling
Empurically based techniques

Instrumental, paleo, and spatial andogues Stochastic models

Link GCM surface climates to observed local climates Atmosphere-surface transier function downscaling 
have been used successfully in many diverse applications, they all suffer in one degree or another from the need to generalize the atmospheric forcing. The underlying assumption here is that similar weather patterns produce similar regional climatic conditions. Although in general this may be true, the over-generalizing of the circulation into a finite range of types results in a loss of power to distinguish finer detail le.g. cold fronts produce cold frontal conditions, but cold fronts may differ substantially from one to another), and in respect to climate change issues falls short of many of the needs of regional impact studies.

Notwithstanding the fundamental subjectiveness of even the actual typing or classification procedure (e.g. Key \& Crane 1986), attempts have been made to circumvent the problem of an over-generalized relationship by using such solutions as a stochastic model to describe the link between weather patterns and local climate (e.g. Bardossy 1994). These approaches, although a significant improvement, still have at their core a generalizing of the weather patterns into a finite number of types. Furthermore, while these accommodate the objectives of downscaling, and in fact in some cases have been termed downscaling, it is suggested that the term 'downscaling' better describes the alternative path of considering the relationship between a sampled state of the atmosphere and the corresponding regional response.

In this, one accepts that the state of the atmosphere is a continuously changing function and not a finite set of discrete states; thus, the objective is to use a set of samples from which to derive the regional climate response to large-scale forcing. In this regard downscaling could be considered as the logical extreme of synoptic climatology, in that every sampled observation is treated as an individual 'type'. Nonetheless, the fundamental approach is different in that one now treats the data as a continuous function in time. Two very different approaches to downscaling are possible:

\subsection{Nested model downscaling}

The typical application in this case is to drive a regional dynamic model at mesoscale or finer resolutions with the synoptic- and larger-scale information from a GCM (e.g. Giorgi \& Mearns 1991, Jenkins \& Barron 1996). In such applications, detailed information at spatial scales down to $10-20 \mathrm{~km}$ may be achieved at temporal scales of hours or less. However, such models are computationally demanding and are, therefore, not an easily accessible research avenue. Furthermore, there are still difficulties to be overcome in the interface between the GCM and the nested model (e.g. how to relate the coarse resolution grid cell data of the GCM, often below the GCM skill scale, to boundary conditions for the far finer scale nested model). Nonetheless, in the long term this technique is likely to be the best solution and needs to be encouraged. To date, however, most nested model applications have been focused on northern hemisphere western nations, whereas many of the nations most vulnerable to global change lie in the southern hemisphere.

\subsection{Empirical downscaling}

The alternative approach of empirical downscaling is computationally efficient in comparison with nested modelling, and is a practical approach for addressing current needs in the climate change research community, especially in many of the countries liable to be most sensitive to climate change impacts. In the empirical approach one seeks to derive quantitative relations between circulation and local climate in some form of $y=\mathrm{f}(x)$. The transfer function is derived from observational data using a mathematical or statistical relationship. The more traditional forms of synoptic climatology rely on statistically generalized functions that categorize the circulation features and their associated climate characteristics; consequently, they are constrained to some degree by the assumptions of the statistical model used and the large within-group variability that generally occurs. In contrast, the methodology outlined here derives a direct mathematical relationship between the circulation and the local climate using Artifical Neural Networks (ANNs), which both removes these constraints and also captures some of the non-linear aspects of the circulation-local climate relationships.

In global change analysis, these cross-scale relationships are derived from observational data and then applied to a GCM circulation data set to derive localscale information consistent with the synoptic-scale forcing of the GCM. This highlights an important additional application of downscaling in GCM validation. Through the application of transfer functions (derived from observed data) to the GCM climate, one implicitiy tests the internal cross-scale consistency and synopticscale forcing of the GCM on regional climates. Applying the same observation-derived transfer function to GCM climate change experiments then allows for the development of regional climate change scenarios at sub-GCM grid-scale resolution, with greater reliability than is possible using the GCM results alone.

Empirical downscaling also opens up numerous other possibilities to investigate processes for which there is no possibility of developing numerical models due to lack of knowledge, or for examining aspects of 
global change not directly represented in GCMs. In this investigative role the relationships may be derived between the atmosphere and, for example, biological or environmental variables, or even societal attributes which have weather dependence such as weather related mortality. The relationships may then be decomposed to examine the underlying principles of the interactions between variables.

\section{CLIMATE CHANGE APPLICATIONS}

For application to climate change issues the empirical downscaling hinges on 3 basic premises:

-that the local-scale parameter is dominantly a function of synoptic forcing,

-that the GCM circulation used to drive the derived relationship is valid at the synoptic-scale,

-that the relationship derived using observed data remains valid under a $2 \times \mathrm{CO}_{2}$ atmosphere

The first premise is implicitly tested in the derivation of the transfer function, while the second is the subject of much ongoing research and has a number of procedures to draw on (e.g. Hewitson \& Crane 1992). An example utilizing Principal Components Analysis (PCA) or Empirical Orthogonal Functions (EOFs) is outlined below. The third premise, that the relationship holds under a $2 \times \mathrm{CO}_{2}$ atmosphere, is the most difficult to justify; however, given that basic laws governing atmospheric dynamics are not about to be transformed, it would seem a reasonable assumption. In other words, the working assumption is that a large proportion of the local climate change will be brought about by changes in the intensity, frequency, and persistence of synoptic-scale circulation features, whose characteristics otherwise are essentially the same as those experienced in the region at present. As a consequence, there will be some residual uncertainty due to possible large-scale changes in, for example, atmospheric water vapor, which could alter the circulationprecipitation relationship, and could also alter the radiative properties of the associated air mass. Similarly, the techniques do not include the direct radiative impact of increased greenhouse forcing on the local climate. As both these problems reflect possible changes in air mass characteristics operating at scales more commensurate with the skill level of the GCM, it is possible that additional corrections for these effects could be derived from the GCM results.

\section{DOWNSCALING APPLIED TO PRECIPITATION}

In the example presented here, a neural net approach is used to derive high resolution precipitation data from the large-scale circulation for a domain that experiences both convective and mid-latitude cyclonic controls. The domain is centered over southern Africa and covers coastal plains and high altitude plateaus, areas of strong topographical forcing, and regions with very sharp climatic boundaries. These produce considerable local variability in precipitation and, therefore, present a particularly challenging environment for downscaling operations. The downscaling procedure adopted here follows a number of distinct steps, as outlined in Table 2, not all of which are required in every application.

These steps are further described in the following sections which present a broad outline of the application. Detailed discussion of each phase of the ANNbased procedure would make for a very lengthy paper, and such details would be better found in other articles (e.g. Hewitson \& Crane 1.994).

1. Selection of domain. Downscaing offers a variety of options for choosing appropriate spatial and temporal scales. In terms of deriving a relationship of the form $y=f(x)$, the atmosphere forms the independent variable whose scale needs to be large enough to capture the synoptic forcing features represented by the GCM. However, in the case of the dependent variable (precipitation in this case) one can choose to work on a wide range of scales from, for example, the basin scale to the scale of the GCM grid cell; similarly, one may choose to use temporal scales ranging from daily to seasonal. Obviously the finer the spatial or temporal scales the more local effects will be an influence and the less clear will be the larger scale forcing.

In this example, a $1^{\circ} \times 1^{\circ}($ gridded daily precipitation data set is produced from approximately 4000 recording stations. Only grid cells containing at least 3 stations are used. For the atmospheric window, an area is chosen that extends between 5 and $10^{\circ}$ beyond the border of the precipitation domain. The size of the domain is such that the major synoptic features-the semi-permanent high pressure systems and mid-latitude cyclones-are represented in the window. The atmospheric data comprise daily sea level pressure (SLP) fields, and $500 \mathrm{hPa}$ geopotential height fields for the period March 1985 to February 1993. The observational data are from the $2^{\circ}$ latitude by $2.5^{\circ}$ longitude Goddard Space Flight Center (GSFC) global assimilated data set (Schubert et al. 1993), while the GCM data are from the Genesis GCM, version 1.02. This version of Genesis is an R15 spectral. GCM incorporating $2^{\circ} \times 2^{\circ}$ land surface, multilayer soil, and sea ice models. Further details on the GCM may be found in Thompson \& Pollard (1995). The GSFC atmospheric data are interpolated to the GCM grid in order to have all atmospheric data on a common grid. 
Table 2. Typical procedural steps in downscaling

\begin{tabular}{|c|c|}
\hline Procedure & Application in example \\
\hline 1. Selection of atmospheric domain, and local climate data & $\begin{array}{l}\text { Atmospheric window from } 0 \text { to } 60^{\circ} \mathrm{E} \text { and } 40 \text { to } 15^{\circ} \mathrm{S} \text { over } \\
\text { southern Africa. Surface climate data are gridded precipj- } \\
\text { tation at } 1^{\circ} \text { spatial resolution over land derived from station } \\
\text { data. Both atmospheric and surface data are daily values }\end{array}$ \\
\hline 2. Reduction of atmospheric data & $\begin{array}{l}\text { Data reduction with Principal Components Analysis (PCA) } \\
\text { and generation of component score time series }\end{array}$ \\
\hline $\begin{array}{l}\text { 3. Comparison of GCM circulation with observed circula- } \\
\text { tion }\end{array}$ & $\begin{array}{l}\text { 3-way correlations performed between the component } \\
\text { loadings from the PCAs of the observed and Genesis data }\end{array}$ \\
\hline $\begin{array}{l}\text { 4. Optional temporal smoothing of atmospheric and local } \\
\text { climate data }\end{array}$ & $\begin{array}{l}\text { Atmopsheric component score time series, and gridded } \\
\text { precipitation data smoothed with a } 5 \text {-day running average } \\
\text { filter }\end{array}$ \\
\hline 5. Optional time-lagging of atmospheric data & $\begin{array}{l}\text { Atmospheric component scores lagged over } 3 \mathrm{~d} \text { to provide } \\
\text { a time history of the circulation }\end{array}$ \\
\hline $\begin{array}{l}\text { 6. Derivation of transfer functions between atmospheric } \\
\text { and local climate data }\end{array}$ & $\begin{array}{l}\text { Artificial neural nets used to derive unique relationships } \\
\text { between atmospheric component scores and precipitation } \\
\text { for each precipitation grid location }\end{array}$ \\
\hline 7. Testing of the relationships & $\begin{array}{l}\text { Evaluation of the relationships using independent ob- } \\
\text { served circulation data to derive precipitation, and com- } \\
\text { parison with actual observed precipitation }\end{array}$ \\
\hline $\begin{array}{l}\text { 8. Application to GCM } 1 \times \mathrm{CO}_{2} \text { circulation data, and evalu- } \\
\text { ation against local climates derived from observed cir- } \\
\text { culation data. }\end{array}$ & $\begin{array}{l}\text { Derivation of gridded } 1^{\circ} \text { resolution local precipitation as a } \\
\text { function of GCM simulation circulation. }\end{array}$ \\
\hline $\begin{array}{l}\text { 9. Application to GCM } 2 \times \mathrm{CO}_{2} \text { circulation data, and evalu- } \\
\text { ation against local climates derived from } 1 \times \mathrm{CO}_{2} \text { simula- } \\
\text { tion circulation data }\end{array}$ & $\begin{array}{l}\text { Derivation of gridded } 1^{\circ} \text { resolution local precipitation as a } \\
\text { function of GCM simulation circulation }\end{array}$ \\
\hline
\end{tabular}

2. Data reduction. Data reduction is carried out using PCA. The S-mode PCA of the observed data generated six SLP and seven $500 \mathrm{hPa}$ components. Overland \& Preisendorfer's (1982) Rule-N test was used to select the number of components retained for use in developing the downscaling transfer functions. The retained components explained 92 and $93 \%$ of the SLP and $500 \mathrm{hPa}$ data sets, respectively. Similar PCAs were performed on the Genesis $1 \times \mathrm{CO}_{2}$ and $2 \times \mathrm{CO}_{2}$ GCM data. In both cases the Rule- $N$ test again resulted in six SLP components (explaining approximately $85 \%$ of the variance) and seven $500 \mathrm{hPa}$ components (explaining approximately $95 \%$ of the variance).

3. Validation of GCM circulation fields. The use of GCM circulation fields to derive local climate values assumes that the synoptic patterns of variance in the model are comparable to those of the observed data. This assumption is tested in what is now a fairly standard manner (e.g. Hewitson \& Crane 1992) by comparing the observed and GCM PCA loading patterns. In this application the loading patterns are compared through a 3-way correlation. Each component from the observational data set is correlated with each of the GCM components. Correlation coefficients are computed on a point-wise basis for each loading pattern, as well as for the north-south and east-west gradients at each point. The average of these 3 correlation coeffi- cients is then used as an index of similarity between the observed and GCM data. Since the component loading maps represent the distribution of coherent variance in the data, this procedure evaluates the spatial behaviour of the circulation. Table 3 shows the best match between the observed and GCM components.

Overall, the centers of variance in the GCM loading patterns match the observed patterns very well, with some small differences in the north-south gradients, particularly in the sea level pressure. Fig 1 shows an example of the component loading patterns (representing variance explained by a component) for 2 typical matching patterns between the observed and GCM data.

As would be expected, the GCM does much better in simulating the $500 \mathrm{hPa}$ flow, and in addition, the GCM components correlate well with components of the observed data which are of equivalent rank. This indicates that the variance of the feature represented by a component has equivalent importance in the GCM climate. Although there are discrepancies in the matching of the ranks, this is explained partly by the fact that the model is simulating artificial years and not necessarily the same real years of the observed data, and that the data sets are of different duration (10 vs $7 \mathrm{yr}$ ). However, some of the mismatch is also likely due to the model actually simulating a represented feature in a 
Table 3. Correlations between the SLP and $500 \mathrm{hPa}$ component loading maps for the GSFC and Genesis data

\begin{tabular}{|c|c|c|c|c|c|}
\hline $\begin{array}{c}\text { GSFC } \\
\text { component }\end{array}$ & $\begin{array}{c}\text { Genesis } \\
\text { component }\end{array}$ & $\begin{array}{l}\text { Average } \\
\text { correlation }\end{array}$ & $\begin{array}{l}\text { Point-wise } \\
\text { correlation }\end{array}$ & $\begin{array}{l}\text { North-south } \\
\text { correlation }\end{array}$ & $\begin{array}{l}\text { East-west } \\
\text { correlation }\end{array}$ \\
\hline \multicolumn{6}{|c|}{ Sea Level Pressure: GSFC and Genesis $1 \times \mathrm{CO}_{2}$} \\
\hline 6 & 3 & 0.91 & 0.96 & 0.81 & 0.96 \\
\hline 5 & 4 & 0.81 & 0.93 & 0.61 & 0.88 \\
\hline 1. & 1 & 0.81 & 0.89 & 0.66 & 0.87 \\
\hline 4 & 2 & 0.79 & 0.91 & 0.68 & 0.79 \\
\hline 2 & 6 & 0.67 & 0.85 & 0.45 & 0.73 \\
\hline 3 & 5 & 0.58 & 0.71 & 0.43 & 0.60 \\
\hline \multicolumn{6}{|c|}{ Sea Level Pressure: GSFC and Genesis $2 \times \mathrm{CO}_{2}$} \\
\hline 6 & 3 & 0.90 & 0.96 & 0.78 & 0.98 \\
\hline 1 & 1 & 0.81 & 0.89 & 0.66 & 0.88 \\
\hline 5 & 4 & 0.80 & 0.91 & 0.60 & 0.87 \\
\hline 4 & 2 & 0.73 & 0.88 & 0.62 & 0.69 \\
\hline 2 & 6 & 0.69 & 0.87 & 0.47 & 0.74 \\
\hline 3 & 5 & 0.51 & 0.65 & 0.30 & 0.58 \\
\hline \multicolumn{6}{|c|}{500 hPa geopotential height: GSFC and Genesis $1 \times \mathrm{CO}_{2}$} \\
\hline 3 & 4 & 0.97 & 0.99 & 0.95 & 0.98 \\
\hline 4 & 3 & 0.94 & 0.98 & 0.92 & 0.90 \\
\hline 5 & 6 & 0.93 & 0.97 & 0.82 & 0.98 \\
\hline 7 & 5 & 0.91 & 0.88 & 0.92 & 0.94 \\
\hline 2 & 2 & 0.89 & 0.96 & 0.85 & 0.86 \\
\hline 6 & 7 & 0.87 & 0.81 & 0.84 & 0.96 \\
\hline 1 & 1 & 0.80 & 0.88 & 0.76 & 0.76 \\
\hline \multicolumn{6}{|c|}{500 hPa geopotential height: GSFC and Genesis $2 \times \mathrm{CO}_{2}$} \\
\hline 3 & 4 & 0.97 & 0.99 & 0.93 & 0.98 \\
\hline 7 & 6 & 0.91 & 0.88 & 0.91 & 0.93 \\
\hline 4 & 2 & 0.88 & 0.96 & 0.81 & 0.88 \\
\hline 5 & 5 & 0.88 & 0.96 & 0.72 & 0.97 \\
\hline 6 & 7 & 0.86 & 0.78 & 0.85 & 0.94 \\
\hline 2 & 3 & 0.83 & 0.94 & 0.71 & 0.84 \\
\hline 1. & 1 & 0.74 & 0.86 & 0.67 & 0.69 \\
\hline
\end{tabular}

manner slightly different from reality. In this latter case, one would anticipate that this difference will be manifest either as loss of variance or as an error in the derived scenarios.

4. Temporal smoothing. The relationship between local climate and the large-scale circulation is a function of both temporal and spatial resolution. The finer the temporal or spatial resolution of the transfer function, the more local effects dominate over the synopticscale controls; thus the greater the spatial or temporal smoothing, the clearer the relationship between synoptic-scale forcing and the local climate variable. In this application the precipitation data were smoothed by gridding the individual station data to $1^{\circ}$ resolution, and some temporal smoothing is now applied with a 5 -day moving average filter. This filtering was found to produce the optimum results after experimentation, and is applied to both the atmospheric component scores and the precipitation data.

5. Time lagging. While the local climate is determined largely by the synoptic conditions at a given moment, the local response may vary considerably depending on the synoptic history and the particular storm track or trajectory followed; therefore, the air mass history contains useful information on the characteristics of the air on the day in question. To accommodate these aspects, the atmospheric data is time lagged over $3 \mathrm{~d}$ such that each day is now represented by the component scores for that day and for the prior 2 days.

6. Derivation of downscaling functions. ANNs are used in this application to derive relationships between the circulation and the local precipitation response. ANNs are analogous in application to multiple regression, with the added advantage that they are inherently non-linear, and particularly robust in finding and representing relationships in the presence of noisy data. The application of ANNs is rapidly becoming more widespread, and further discussion and references on their utility for downscaling applications may be found in Hewitson \& Crane (1994). ANNs have proved particularly effective in downscaling precipitation, where there is a significant non-linear relationship that more traditional techniques such as regression do not capture well. 


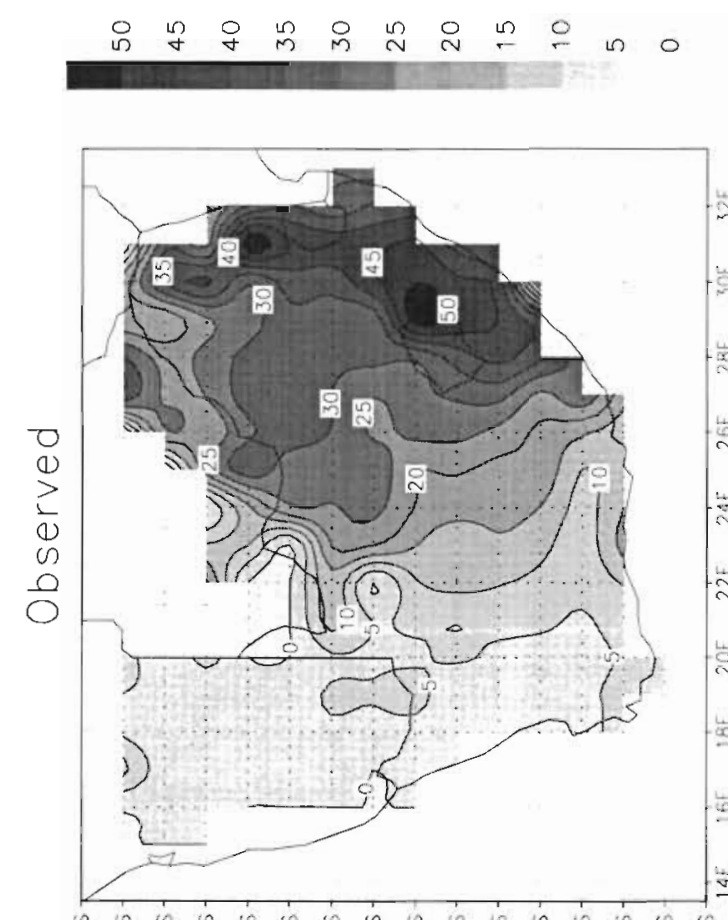

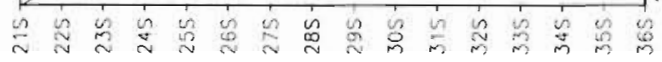

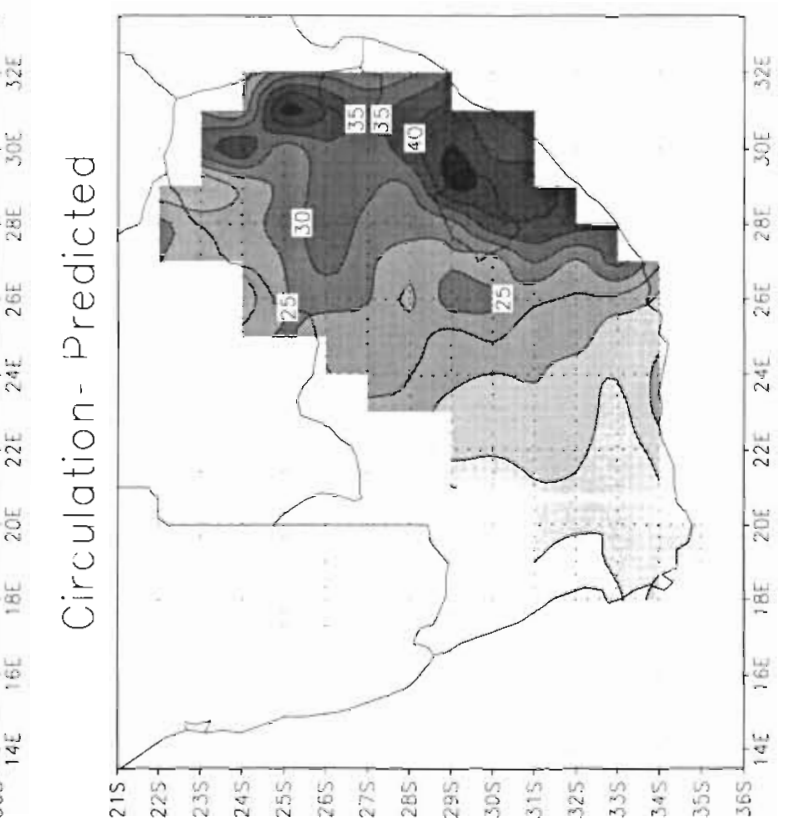

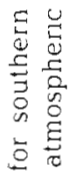

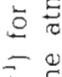

$\zeta \succeq$

區

을

응

뭉

记

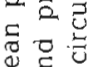

है

동을

氙离

语莙

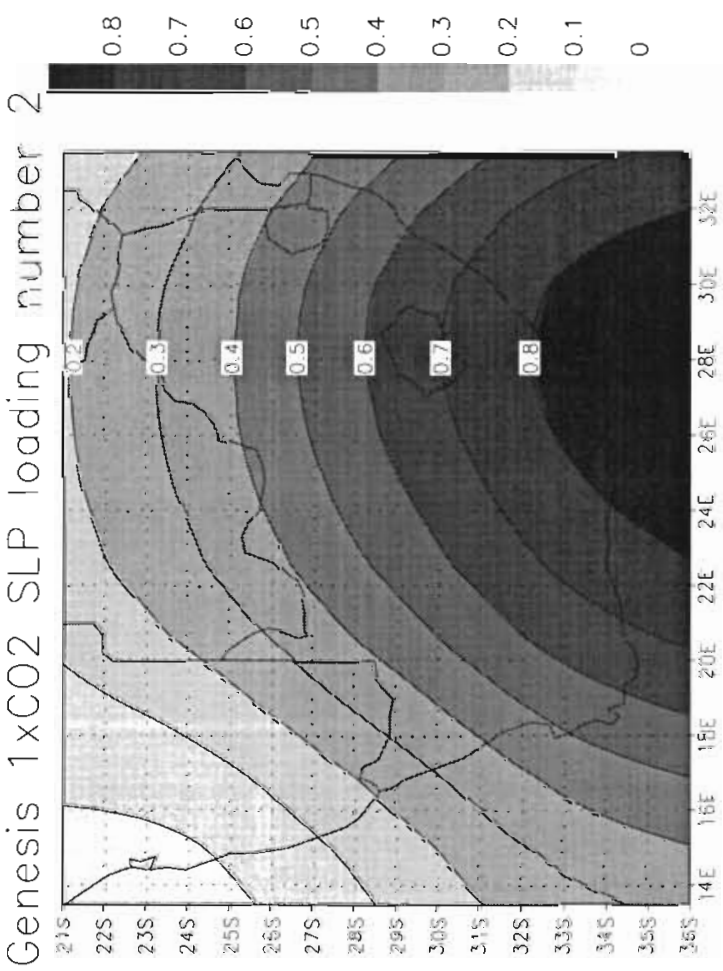

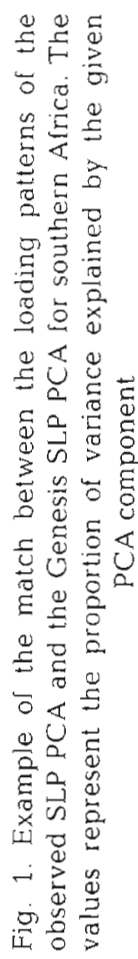

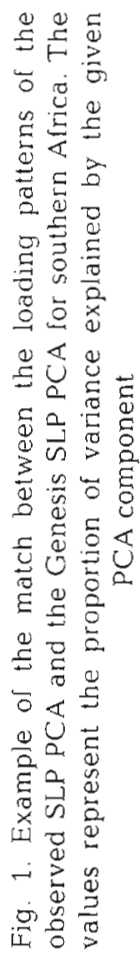


In this application ANNs learn the relationship between the atmospheric circulation, represented by the lagged component scores, and the local precipitation at each $1^{\circ}$ grid cell. A 5 yr subset of the component score time series from the GSFC observed assimilation data and the gridded observed station precipitation is used to train an ANN for each location, and the relationship is then tested against the remaining $2 \mathrm{yr}$ of data. In all cases the ANN model is developed to predict the actual daily total precipitation, and not, as could be the case, the anomaly pattern which would then subsequently be added to some mean field. The more demanding task of predicting the daily total strengthens the credibility of the relationship as it indicates that the ANN model is capable of capturing not only the difference between synoptic events, but also the actual total precipitation represented by a synoptic event.

7. Testing the downscaling relationships. The local precipitation for the independent test data is derived
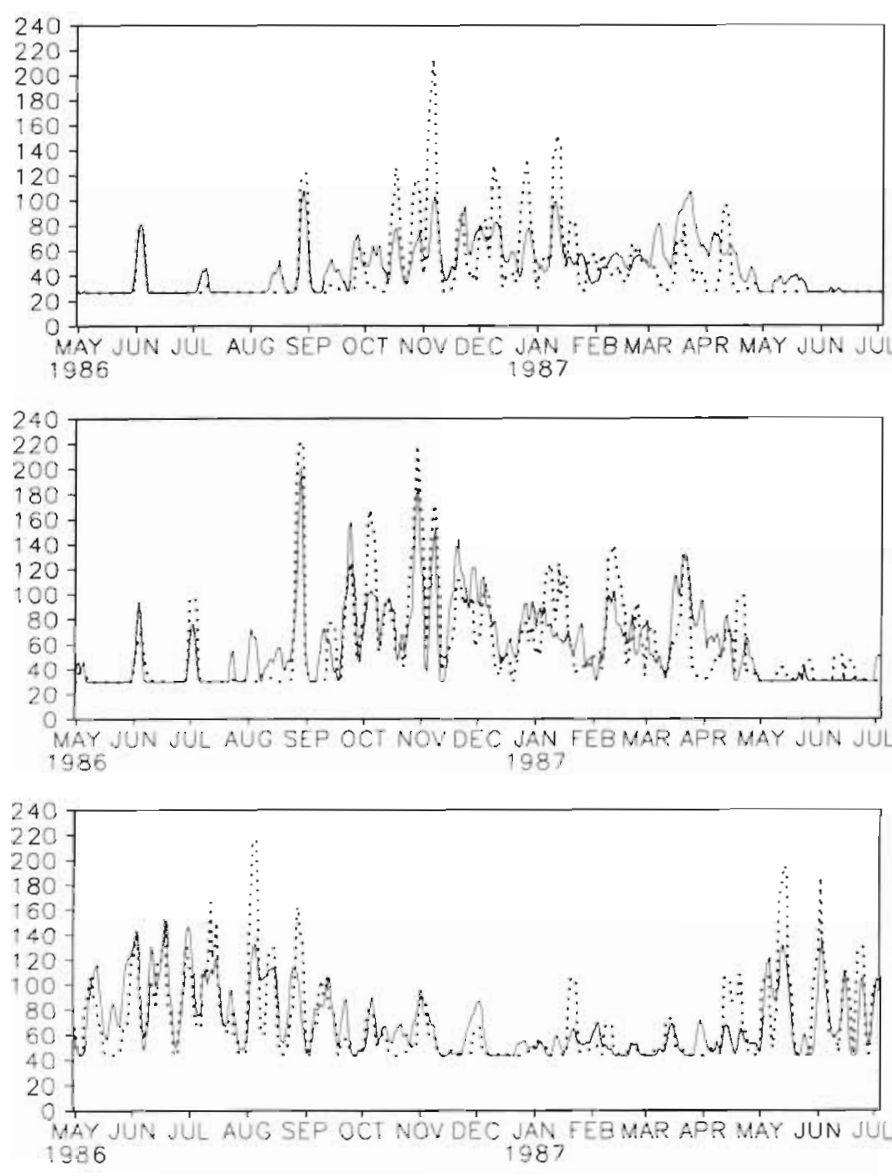

Fig. 3. Time series of observed and circulation-predicted precipitation for 3 grid locations $\left(10 \times \mathrm{mm} \mathrm{d}^{-1}\right)$. Dotted lines are observed, and solid lines are predicted. Grid locations from top to bottom: $34^{\circ} \mathrm{S}, 19^{\circ} \mathrm{E} ; 32^{\circ} \mathrm{S}, 28^{\circ} \mathrm{E} ; 27^{\circ} \mathrm{S}, 27^{\circ} \mathrm{E}$ from the ANN and compared against the actual observed precipitation. Fig. 2 shows the mean summer precipitation pattern (December, January, February) for the gridded observed data, and for precipitation derived directly from the observed circulation (circulation-predicted) with the ANNs. As can be seen, the ANNs appear to capture the spatial distibution and amount of precipitation as a function of synoptic forcing with considerable accuracy.

Further evaluation of the relationships can be made by comparing the time series of observed and circulation-predicted smoothed daily precipitation for selected grid cells. Fig. 3 shows time series from 3 grid cells (located at $34^{\circ} \mathrm{S}, 19^{\circ} \mathrm{E} ; 32^{\circ} \mathrm{S}, 28^{\circ} \mathrm{E}, 27^{\circ} \mathrm{S}, 27^{\circ} \mathrm{E}$ ) which represent a winter mid-latitude cyclone controlled regime, a regime with strong orographic influences, and a summer convective rainfall regime in the northeast. In all cases, the ANN is very successful in capturing the phase of the events and is reasonably successful in predicting their magnitude. The errors in magnitude tend to average out, as is seen by the seasonal mean maps, and are partly due to the lack of water vapor information in the relationship. For example, the ANN learns a generalised relationship, and produces the same precipitation each time for a given circulation. However, for similar circulation states but different atmospheric water vapor levels, one would expect different precipitation results. Nonetheless, the ANNs demonstrate a satisfactory ability to derive local precipitation as a function of synoptic forcing.

It should be noted that while the ANNs have now been trained for further application to the GCMs, the possibility also exists of simply investigating the relationship represented by the ANN. In this case one would be looking for information about what the ANN has identified as being of importance in the relationship, for example the relative importance of one input variable versus another. See Hewitson \& Crane (1994) for further examples of this aspect of ANN use.

8 and 9. Application to GCM circulation. The final 2 stages in order to reach a climate change scenario are to apply the relationships to the GCM circulation data, represented again by a component score time series. Two comparisons are made here: first, precipitation derived from the circulation of the control $\left(1 \times \mathrm{CO}_{2}\right)$ simulation circulation is compared with the observed circulation-predicted precipitation for GCM validation and diagnostic purposes; second, the doubled $\mathrm{CO}_{2}$ circulation-predicted precipitation is compared with that derived from the $1 \times \mathrm{CO}_{2}$ circulation. 
In the former case, comparing the control simulation with the observed, one is able to evaluate the GCM synoptic circulation in terms of specific consequences at the local scale; the precipitation derived from the observed circulation is used as the basis of comparison in order to compare like with like. As the observed circulation-predicted precipitation is so close to actual precipitation, the difference in this case is minimal. Fig. 4 shows the mean summer precipitation derived from observed circulation and from the GCM control simulation. At first appearance the GCM seems to perform well, having produced a very similar spatial pattern; however, it can be seen that the GCM forcing significantly overpredicts rainfall over the east coast of southern Africa. This results from a south Indian semi-permanent high pressure system that is located too far south in the GCM. Nonetheless, the GCM appears to force reasonable local precipitation patterns, which can then be compared with the rainfall produced in the $2 \times \mathrm{CO}_{2}$ simulation

The results of the comparison between $1 \times \mathrm{CO}_{2}$ and $2 \times \mathrm{CO}_{2}$ circulation-derived precipitation is shown in Fig. 5 as an anomaly map for the summer rainfall period. The GCM shows a clear reduction in precipitation over the summer rainfall region and reveals distinct regional differences. Note that the regional detail is far greater than can be obtained with the GCM on its own, which, in this case, covers the entire region with only 3 grid cells! The $1 \times \mathrm{CO}_{2}-2 \times \mathrm{CO}_{2}$ differences translate to approximately a 10 to $20 \%$ reduction in the regional rainfall, which indicates significant consequences for an area already subject to high rainfall variability.

\section{CONCLUSIONS}

Today's society is faced by the dilemma of whether to invest in the significant cost of developing mitigation and adaptation strategies for climate change impacts, or to risk the equally significant consequences of present inactivity should a major human-induced climate change occur in the relatively near future. As the political process must respond to a complex set of often conflicting pressures and objectives, the formulation of global change policy requires thorough understanding of the likely changes that may occur in the global environmental system.
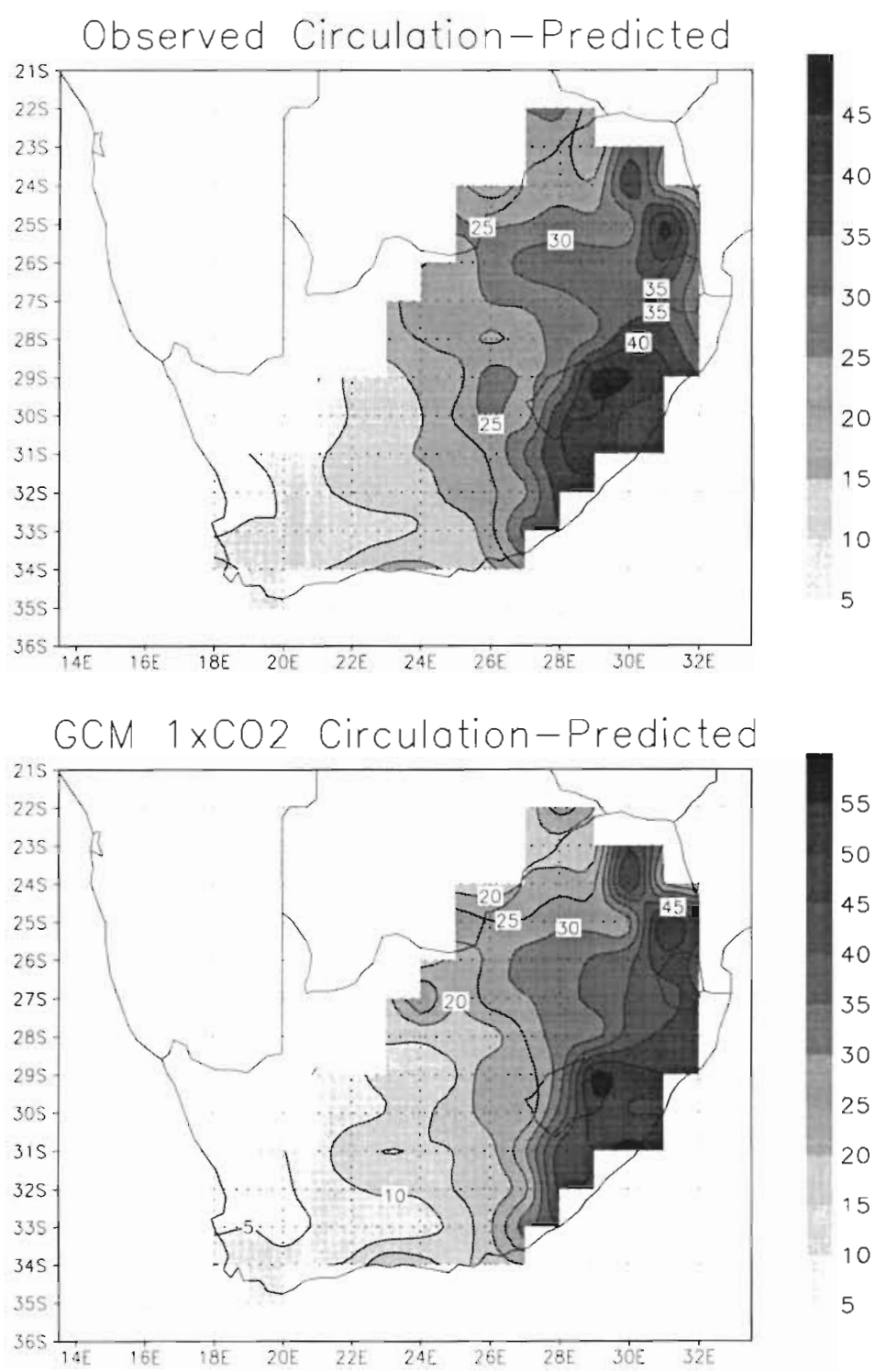

Fig. 4. Summer (DJF) mean precipitation $\left(10 \times \mathrm{mm} \mathrm{d}^{-1}\right)$ for southern Africa: observed circulation-predicted and GCM $1 \times \mathrm{CO}_{2}$ circulationpredicted

The research base needs to come from the broad field of physical sciences, all of which, to some degree, require climate change scenario information as a fundamental point of departure. For example, water resources are a critical component of the economic structure in many regions of the world; however, developing the infrastructure necessary to adapt to changing water resources often requires long planning lead times. Although, in some cases, it may be possible to identify projects that would be beneficial regardless of whether any change actually occurs, for many others it may be difficult to justify the expense involved without the availability of reliable climate change information at the required spatial and tempo- 


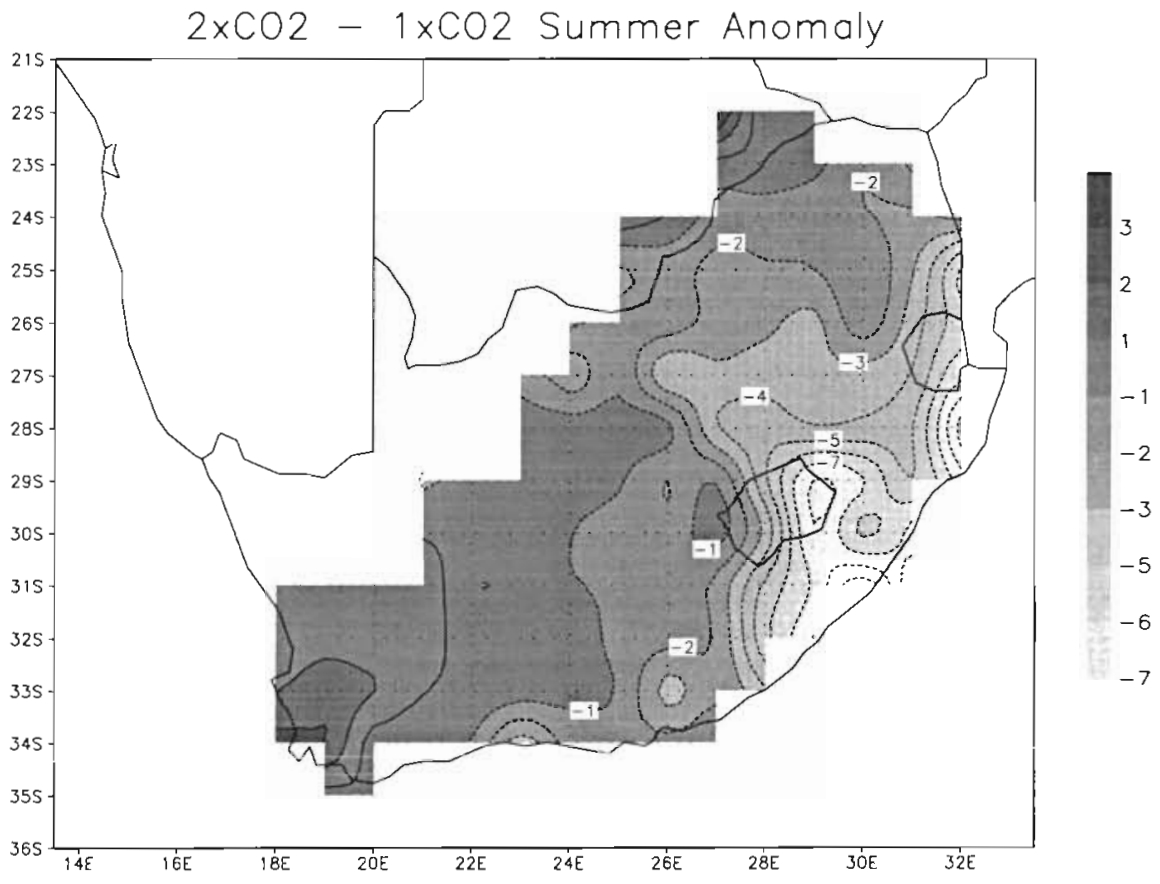

Fig. 5. Summer (DJF) $2 \times \mathrm{CO}_{2}-1 \times \mathrm{CO}_{2}$ precipitation anomaly map for southern Africa $\left(10 \times \mathrm{mm} \mathrm{d}^{-1}\right)$

ral scales. The only viable tools for such research are GCMs, yet these have intrinsic limitations for which downscaling, either through dynamical process based nested models or as empirical transfer functions, can prove a valuable solution. While the nested modelling avenue promises to be the optimum long-term solution, empirical relationships provide an immediate computationally efficient approach to tackling some of these research questions. The example provided for southern Africa demonstrates the effectiveness with which downscaling can translate from the GCM's skill level down to the spatial scales necessary for assessing societal impacts.

In addition, as a further development of traditional synoptic climatology, downscaling offers a technique applicable to a wide variety of other research questions. For example, when coupled with GCM simulations, downscaling provides a diagnostic methodology for validating scale relationships in the model, or for use in multi-variate inter-model comparisons. Alternatively, in investigating the large-scale dynamics of the global system through model sensitivity and perturbation studies, downscaling is an effective means of interpreting the local and regional consequences of such large-scale processes.

However, it is with issues of global climate change and variability that downscaling can assist the most, providing a mechanism for assessing changes in regional climate at the scales most beneficial to society.
Acknowledgements. The Earth System Science Center at Penn State University, the Water Research Commission of South Africa, and the comments of 2 reviewers are gratefully acknowledged for their assistance.

\section{LITERATURE CITED}

Bardossy A (1994) Downscaling from GCMs to local climate through stochastic linkages. In: Paoli $G$ (ed) Climate change, uncertainty, and decision-making. Institute of Risk Research, University of Waterloo, Ontario, p 29-45

Barry RG, Perry AH (1973) Synoptic climatology: methods and applications. Methuen \& Co, Ltd, London

Giorgi F, Mearns LO (1991) Approaches to simulation of regional climate change: a review. Rev Geophys 29 $191-216$

Grotch SL, MacCracken MC (1991) The use of general circulation models to predict regional climatic change. J Clim 4: $286-303$

Hewitson BC, Crane RG (1992) Regional-scale climate prediction from the GISS GCM. Palaeogeogr Palaeoclimatol Palaeoecol (Global Planet Change Sec) 97:249-267

Hewitson BC, Crane RG (eds) (1994) Neural nets: applications in geography. Kluwer Academic Publishers, Dordrecht

Jenkins GS, Barron EJ (1996) General circulation model and coupled regional climate model simulations over the eastern United States: GENESIS and RegCM2 simulations. Global Planet Change (in press)

Key J, Crane RG (1986) A comparison of synoptic classification schemes based on 'objective' procedures. J Climatol 6:375-388

Overland JE, Preisendorfer RW (1982) A significance test for principal components applied to cyclone meteorology. Mon Weather Rev 110:1-4 
Schubert SD, Pjaendter J, Rood R (1993) An assimilated data set for earth science applications. Bull Am Meteorol Soc $74: 2331-2342$

Thompson SL, Pollard D (1995) A global climate model (GENESIS) with a land-surface-transfer scheme (LSX). Part 1 Present-day climate. J Clim 8:732-761

Editor: H. von Storch, Geesthacht, Germany von Storch H, Zorita E, Cubasch U (1993) Downscaling of global climate change estimates to regional scales: an application to Iberian rainfall in wintertime. J Clim 6 : $1161-1171$

Yarnal B (1993) Synoptic climatology in environmental analysis, a primer Belhaven Press, Boca Raton

Manuscript first recelved: March 7, 1996

Revised version accepted: September 9, 1996 